\title{
Community tourism - Development of rural areas in developing countries
}

\author{
Monika Nova ${ }^{1,2, *}$ \\ ${ }^{1}$ Charles University, Department of Legal History, nám. Curieových 901/7, 11640 Prague, Czech \\ republic \\ ${ }^{2}$ Charles University, Department of Psychosocial Sciences and Ethics, Pacovská 4, 14021 Prague, \\ Czech republic
}

\begin{abstract}
.
Research background: Community-based tourism has become a very popular form of sustainable tourism in the world. Tourism is supposed to be developmental in nature benefiting the local community by improving the Quality-of-Life and the standard of living for locals and local commerce. It is therefore imperative to understand that the community around tourism development is important and has to be involved in the development from the initial planning of the development as the sole beneficiaries of the development.

Purpose of the article: The aim of this work was to evaluate the prerequisites for the development of community-based tourism and Bridging the technology gap for community-based tourism projects in Cambodia.

Methods: The theoretical part is focused especially on community-based tourism, its origin, history and possibilities of development. The practical part of the thesis consists of a descriptive part which characterizes the studied area from the point of view of living conditions and tourism, and, also, contains the results of analysis of interviews conducted conditions and tourism, and, also, contains the results of analysis of interviews conducted with the local people and person by the implementer during the stay in the Cambodia were analysed using the Grounded theory method.

Findings \& Value added: The result of the paper is to set the prerequisites for the development of community-based tourism and recommendations for a subsequent research.
\end{abstract}

Keywords: aid; community; developing country; tourism

JEL Classification: $J 15, R 23, Z 32$

\footnotetext{
* Corresponding author: monika.nova@htf.cuni.cz
} 


\section{Introduction}

This paper is an output of our stay in Cambodia in 2019 / 2020. The issue of tourism possibly developed in the area of our interest was from its inception associated with the author's idea (or rather research question) of utilizing the tourist industry for the development of local communities.

Cater, Garrod and Low [1] regard the tourism as an approach maintaining biodiversity, strengthening local communities and supporting economic development. The authors believe that tourism brings these benefits especially to the developing countries of Africa, Asia and Latin America. Local communities engaged in the community-based tourism (primarily from rural areas) cater for tourists in their villages, jointly manage all their activities and share profits. Fairly typical is forging all kinds of alliances. This type of tourism will allow the visitors to get the first-hand experience of the community's culture and living environment. The communities are mostly well aware of the value lying in their cultural and natural heritage, and this awareness leads them to take proper care of the inherited resources.

Towner [2] among others, considers that the history of community-based tourism has always been documented from the "western" angle and perceived as repeated trips of the higher- (and later on even the middle-) income groups of people. This author also believes that much closer attention should be given to the "non-western" societies and cultures.

Beeton [3] reminds us that the role played by local inhabitants in the development of tourism was addressed for the first time as early as 1985 in Peter E. Murphy's book "Tourism: a Community Approach". No matter how often the book was quoted, the importance of communities for tourism was properly noticed no earlier than the end of the 20 th century, specifically at the moment when mass tourism produced damaging effects and the issue of sustainability became apparent [4]. In 1992 D. Pearce published "Alternative tourism: Concepts, classifications and questions" where the author presented the community-based tourism as a pursuit offering each participant affected by the activity a fair share in the flow of its benefits, and a say in collective decisions and local control of the effort [3]. The community-based tourism is commonly understood to be an activity regulated by the community alone and performed primarily by the local service providers in cooperation with other communities, with the local administrative apparatus, government agencies and non-government organizations [5].

Encountered in literature can be a whole range of terms describing basically the same concept - for example rural community travel and community eco-tourism [1,6], gastrotourism and others.

\subsection{Theoretical basis}

Yeo etd. [7], among others, considers that, The society in general has acquired valuable knowledge through the birth of "information society" the development of information and communication technologies and this has generate many new opportunities and choices for the general public as information and communication technologies has changed their learning, working and personal lives. The emergence of I information and communication technologies played a key role in alleviating poverty as it has the capacity to generate employment opportunities. However, in this day and age, there are some pockets of the world's population that are unable to enjoy the benefits of information and communication technologies as a result of the existence of access barriers, high costs and minimal human resources. This is even more evident in an environment of isolation, relative deprivation, 
and dependence that there are insufficient attention given to the indigenous people towards information and communication technologies usage.

The researchers e.g., Ahn, Lee \& Shafer [8]; Nova [9]; Chandralal [4], have evidenced that communities' supports are vital in ensuring long-term success in tourism development and the fact that it is impossible to sustain tourism to a destination that is not supported by the local people. Hence, it is important to understand their perceptions of tourism and how have tourism affect their livelihood from the perspectives of social, economics, environmental and cultural.

The concept of Community-based paves the way for new lines of investigation and for the possibility of tourism development together with other alternatives such as Pro-Poor Tourism (PPT); Community Benefit Tourist Initiatives (CBTIs) and Community-Based Enterprises (CBEs) the authors Manyara \& Jones [10]. López-Guzmán, Cañizares, Pavon [11] among others, considers that summarise, all these initiatives agree that the destination community should be included in the tourism planning and management decision-making process, owed to three main reasons: it considers them to be part of the tourist product, local communities adapt to changes easily, and it helps to open their minds.

Aspects of community-based tourism

Asker et al. [5] and some other authors describe the aspects typical of the communitybased tourism as follows:

- $\quad$ it benefits the local communities, particularly village people and local inhabitants; the effort must be helpful to them and is supposed to improve their cultural and environmental conditions;

- it is characterized by offering the tourists accommodation with the local community;

- $\quad$ all the tourist-oriented activities are communally coordinated;

- the profits are always shared equally;

- the profits are invested in developing the community and/or in preserving the community's cultural and natural heritage;

- $\quad$ the community is engaged as early as the planning stage of the tourism business.

Characteristics making a destination suitable for this kind of tourism

(Aprende de turismo) [12]:

- the original community has to be authorized to manage and/or exploit local resources;

- communities previously excluded from development programs are expected to benefit from the "triangular cooperation" (TRC);

- the area must offer not just great cultural heritage but also tourist sights and resources making the destination attractive;

- natural environment has to be properly protected, just like the local community customs and traditions;

Advantages of the community-based tourism (Aprende de turismo) [12]:

- $\quad$ it raises the quality of life enjoyed by the local inhabitants, allows them to access the vital services and makes them less vulnerable;

_ $\quad$ it alleviates the problem of migration to cities and strengthens social coherence;

- it boosts family income and thus improves school attendance of kids;

- $\quad$ it allows the communities to access services previously inaccessible for them;

- $\quad$ it is protective of water resources, ecosystems, flora and fauna.

The community-based tourism was pioneered by Ecuador, a country considered to be a leader in community eco-tourism, where tourism ranks as the third most important economic activity. 
The topics of tourism and communities in developing countries have been implemented in the last two years and their research is published in the web of sicence, for example:

Aziz [13] his study attempts to examine the way in which rural tourism is developed by using the Appreciative Inquiry (AI) approach as a research tool. AI is an increasingly important area as it was able to offer a positive and strength-based approach to the rural community development. It can be seen as an alternative tourism research tool for community development as far as rural tourism is concerned. The author Olya [14] and the article argues and the results revealed that community attachment, community involvement, and perceived benefits had a significant and positive impact on SSTD. The results of the metric invariance tests show that the effects of community attachment and community involvement on SSTD (support for sustainable tourism development) varied across the community groups at this world heritage site located in a developing country. The study discusses the theoretical and managerial implications of these findings. The author Strydom [15] indicates Sustaining the community/particular communities has therefore become an essential element of sustainable tourism. The rationale of sustainable tourism development usually rests on the assurance of renewable economic, social and cultural benefits to the community and its environment. The author Yasa [16] and his study aims to examine community empowerment in the development of tourism in the digital era in North Badung (Indonesia), Badung Regency. The quality of the community needs to be improved through community empowerment with education and training in accordance with the needs of the digital era.

The authors Matiku, Zuwarimwe and Tshipala [17] describe that communities play an important role in the process of tourism development and their support is essential for the development, planning and successful operation of tourism development, and for attainment of sustainable livelihoods. Furthermore, an all-stakeholder-oriented model is proposed where the community is at the centre with an element of co-management with other sectors, bearing in mind the sustainability of communities' livelihoods. Their paper presents a review of various planning and management strategies that have been used for community-driven tourism projects and also identifies some case studies where applications of some of these strategies have worked. The author Gunawan, Yuli, et al. [18] in their article they write that village tourism program is one of programs that can boost positive contributions to community development. Their study aimed to design an independent community building model through environmental-based tourism management. A participative community empowerment became the main instrument to increase environmental living standard and preservation. Based on the mapping of problem patterns, the crucial programs to develop covered tourism awareness community, joint business group and integrated waste management efforts. The authors Mayaka, Lacey, Rogerson [19] and their paper explores the 'alternative' empowerment roles of catalyst, facilitator and advocate in community-based tourism in the context of community development practice, drawing on findings from four community-based tourism (CBT) ethnographic case studies in Kenya. A 'friend' or 'neighbour' relationship is uncovered as a possible combination of these roles. The various roles may be points or positions in a continuum, a relationship that develops over time. The roles could be realised between a community and an individual from within or outside the community. It is further proposed that understanding the roles and the relationships provides possibilities for community empowerment and sustainable community development within CBT settings. Author Armin Falk et al. [20] and his article studies the global variation in economic preferences (preferences for community tourism). Variation in preferences is also correlated with economic behaviors. Across countries, preferences vary with aggregate outcomes ranging from per capita income, to entrepreneurial activities, to the frequency of armed conflicts. Authors Tosun et al. [21] have arguing that the local people's positive place- image perception about and support for 
tourism development in their residential area may not be sustained unless further supportive measures are taken by local and central governments. Author Nova [22] discus about the social globalization manifests itself in the emergence of links newly developed between societies and people generally. The cultural globalization intensifies contacts among cultures, spreads cultural phenomena and supports cross-cultural exchange. [23] they publish that Travelers in community tourism demand authentic, experientially-oriented opportunities with more meaningful interactions with locals. This can be done through sharing the host's living space in particular, thereby establishing a closer relationship with the host and the guest feeling more immersed in the experience. Sociability factors are also important, as they can lead to authentic experiences through exposure to the local culture. Familiarity and contentment is usually engendered through artefacts which reflect the host and the location.

\section{Methodology}

This qualitative research was conducted among experts on community tourism who operate in Cambodia. We sought the experts' opinions on technological gap in the projects of community tourism. This group of participants was chosen on the strength of their managerial expertise which made them qualified to assess the importance that the technologies might have for the community tourism.

The data were analyzed using the grounded theory method and its open and axial coding techniques.

The participants were chosen by the method of simple purpose-oriented selection. To qualify, they were supposed to operate in the country for over three years; to be engaged in the relevant projects in a managerial position; and to agree to be interviewed.

Defining the problem - research questions:

The research was to analyze the possible ways of bridging the technological gap existing in the projects of community tourism in Cambodia from the viewpoint of experts engaged in the field.

The research questions were:

- To what extent and in what manner is the technological gap in community tourism projects currently gapped?

- What impacts on the future development of community tourism can be expected of technologies / digital abyss?

Data recording and processing:

The interviews were recorded. All participants were aware of being recorded and they granted their consent to the author. When recorded, the interviews were verbatim transcribed and the transcripts were then coded and analyzed.

The open-coded data were systemized and clustered into larger wholes, i.e. categories, in consideration of their similarity. Strauss and Corbin call this process simply "categorization". Subsequently, the data were coded also axially, with the process being a loose follow-up to the previous open coding. In that step the categories and subcategories constituted in the first coding were rearranged according to links newly revealed. This coding aimed to find new stable bonds and new categories offering stable properties and characteristics. [24].

Data interpretation; practical recommendations:

The data thus obtained (after being analyzed by the methods of open and axial coding) were interpreted. They were split into categories that emerged from the accomplished analysis.

Then the interpreted data were described (in conjunction with Ms. Jitka Marková) and accompanied by a practically biased commentary supported by relevant arguments. 


\section{RESULTS}

\section{- digital revolution}

The digital revolution is dominating the tourism industry. The statistics from 2018 show that just over $75 \%$ of all holidays were booked online. (TrekkSoft) [25].

The reality is that most of us, when booking travel, just go online, search, check reviews and book. An instantaneous process.

The travel industry today is heavily dominated by the international online travel agents (OTA's) the likes of Booking.com, Agoda, TripAdvisor, Expedia etc, all with highly integrated platforms and heavy investments in online marketing and search engine optimisation. Rarely are the top Google's search pages not filled with the OTA's pages. The industry's love-hate relationship continues with them, with smaller online competitor platforms often the subjects of takeover and investment by the OTA's. The OTA's strengths are primarily in marketing, promotion and booking system integration of the hotels and guesthouses. This is fantastic for hotel owners, as they just add room descriptions and photos, connect to their booking system and take bookings. For a community running a homestay in a rural village this one-size-fits-all approach simply doesn't work.

This leaves the vast majority of locally run community based tourism initiatives being left behind without the necessary skills, knowledge and conceptual understanding of the digital revolution taking over the tourism industry. The digital gap is gigantic, with the expectations of international visitors being light years ahead of where the local rural communities in developing countries reside. There is no easy way to bridge this gap. A holistic innovative solution needs to be implemented to bring local Community-based tourism (CBT) projects online, and support them to stay online.

Currently, the most common solution is an NGO or government building a low-cost website for the CBT project; by doing so the community gains an online presence and opportunity to showcase their tourism experience to potential visitors. However, in reality, these websites are frequently damaging to CBT projects. Donor funding is used to hire web developers, content writers and media and marketing are used to build a website that nobody from the community knows how to manage, update or respond to visitor queries. More often than not, communities do not even understand the reason why they have or need the website and how it can help them to achieve their ambitions. Solutions are being developed without taking into consideration the communities literacy levels, - in many cases a total absence of digital literacy - or their inability to generate new digital content. Due to the limited nature of donor funding, after the initial investment or project is completed, the websites are left unmanaged - not updated, without new information about services, prices, contact details etc. This results in frustrated visitors who try to use the outdated websites to plan their holidays. Human-centred design is required to tackle the digital divide for CBT projects.

Impact Explorer Cambodia (impactexplorer.asia) is an online marketplace that brings local community based tourism projects and ecotourism initiatives online and by doing so it offers more sustainable choices to international visitors. We work exclusively with community-based tourism projects and NGO run environmental projects, rather than single family run homestays.

\section{- digital divide and challenges}

Over the last 3 years, we have been faced with the realities of the extent of the digital divide and the gap community-based tourism projects have to overcome in order to go online and stay online. Here are some of the challenges we have faced, and solution we have developed: 
- Lack of basic understanding of how the internet works and of how most people in developed world use it - even though most Cambodians own a mobile phone, and the vast majority of people have some access to the internet, this is far from having full access to digital information.

The two initial challenges identified were: 1) penetration of smartphones and 2) funds to provide enough mobile data for smartphone use.

In our quest to solve these problems we quickly formed an opinion that the problem was much deeper - in that the barrier was understanding "how" information exists on internet and how people interact with it. In Cambodia the vast majority of all internet use is done through Facebook or YouTube. For most Cambodians Facebook "is" the internet. The concept of "Googling it" is absent, and if Google is used, many Cambodian internet users simply cannot validate the source of the information - (authority, genuineness, trust etc) and choose the most relevant information they are searching for. Therefore, the CBT project members did not understand the basic premise of an international traveller sitting in their home and searching for places to visit and then booking a holiday. The issue is simple, up-to-date and relevant information is not a reality for most people in Cambodia in their everyday lives.

In overcoming this challenge, we decided to take a different approach, and instead of trying (and failing) to have the information sent to us from the community, we now keep in regular contact with community members and poll them for the essential information changes as part of everyday conversation.

- Lack of digital literacy - For most Cambodians Facebook is used as their main communication tool, via messenger and Facebook voice calls. Beyond Facebook, technology is a mystery to most villagers. Therefore, using online booking forms, online messages or emails is simply not feasible. Old-fashioned phone calls, Facebook calls or messages are the most common way for us to communicate booking information with the CBT projects.

- Literacy levels are poor - Don't we all love a good efficient online booking system, with automated booking emails and reminders? Here, forget it! How is someone with poor literacy levels going to read your message? The risk of misunderstanding is just far too high. Recorded Facebook voice messages become a far more practical option in these situations.

- Content creation - Language, language, language is a major issue, but not the biggest one as we found. Great content can be translated and great photos do not need any words, however we quickly found that some ideas and concepts do not cross cultures. With the exception of a few unique individuals, most local CBT members and even local NGO staff, struggle to identify stories international visitors from developed countries are interested in reading. Similarly, in choosing photographs that would make them want to make a booking. From our discussions, it is not a language issue but a different point of view - a lens through which an international content writer sees the local experiences. Without both a financial and human resource investment in creating unique, high quality content for presenting digitally, you might end up with text resembling an instruction manual for your washing machine, not compelling content for your website.

\section{- online payments}

Online payments are complex issue in most developing countries, many with low penetration of the full range of mobile and bank payment options seen in developed countries. With financial inclusion in mind, we have spent a significant amount of time trying to lower this barrier to entering the ecommerce world. The solutions are not easy or cheap, however there are other more complex issues at play - such as trust and confidence that the community will receive their money. This was initially an issue for us, as many of the villagers wanted to receive their money in cash - payment on arrival by tourists, as they 
feared that if we have their money, we might not transfer the money to them at all. This clearly shows that financial trust is very low in the community between the members of the CBT project but also in the wider sense. We have invested significantly in discussions on the concept of online booking, the flow of payment and the process used to communicate information at each stage. How funds flow from traveller to community? In many cases, we started with a cash-based system, in order for the community to initially validate our communication and build trust. Shortly afterward, sometimes within only a few weeks, we moved to online and digital payment following the same process. As soon as communities understood the process, we introduced further benefits to the online system by guaranteeing income in cases of no show by tourists by taking payment by card at the time of booking. As with many similar technology introductions, the issue of online payment eventually became irrelevant.

After 3 years and 45 CBT projects in Cambodia being online and taking card-based bookings, it is important to highlight that the process is not easy or cheap. CBT projects are not ready to "jump" online, nor do they currently have the skills and technology understanding to do so.

On the other hand, most NGOs or government departments of tourism do not have the in-depth understanding of marketing and ecommerce to support the CBT project either. The only way communities can be brought online is through truly collaborative communityprivate sector-civil society partnerships with a support from a visionary funder who understands the benefits of investing in community development through technology and marketing.

Impact Explorer exist as the bridge to fill the gap between the digital world of visitors coming from developed countries and the 'analogue' world of poor rural communities in Cambodia and the region. With every new booking we bring these two worlds closer; not only closing the digital divide for CBT communities but also delivering positive impact for poor rural families.

\section{Discussion}

The entire tourist industry has recently been undergoing an extensive change closely related to social changes in general. The subject of sustainability is coming to the fore in all aspects of human life, accompanied by the threat of exhausting our non-renewable natural resources. An occurrence strong in modern societies lies in the tendency of some people, particularly the richer upper class people, to abandon consumerism and embrace a simpler, less materially oriented way of life, sometimes mushrooming into an extreme form known as minimalism. They typically wish to return to lifestyle as it was lived before modern technologies prevailed, and resurrect the natural substance of human existence.

All these changes can follow from a sense of superfluity that people in some developed countries enjoy, being overwhelmed by excessive affluence. As regards tourism, the changes result in a growing demand for alternative forms of the business (e.g. eco-tourism, agro-tourism, cultural tourism and the like) which would emphasize environmental, social and economic sustainability and impose curbs on mass travelling. Growing interest in such activities then offered some market scope for the entry of a broader range of participants and players able to appreciate this new source of income and livelihood. There are many regions, primarily in the developing countries, where tourism has supplemented the income of local population, which it true especially of the community-based tourism in which the community itself manages all the related activities and keeps home all the earnings. Tourism has thus become a tool of development instrumental in improving living conditions not only in Cambodia but in other countries too. 
Regions and districts of some states in south-east Asia, Africa, Latin America and the developing countries generally have to combat the problems of poverty and, quite often, utter destitution. The rural areas of the central and south American countries, south-east Asia, Africa are home to a multitude of people who make their living mainly in agriculture. Regrettably, their ways of cultivating land and raising livestock are frequently not sustainable and not beneficial for their standard of living, though agriculture is their sole source of livelihood. The members of rural communities, prevalently young people, are then inclined to escape the difficulties of village life by moving to cities, and this demographic drift aggravates the problem of excessive urbanization. Unfortunately, lacking education and therefore unable to land a decent job, they end up in slums and live in abject poverty.

The rural areas offer typically just a limited latitude for development, and the problem is made even worse by the government institutions failing to support such areas, oblivious of the importance that agricultural produce has for the workings of society. Minor agricultural producers, exploited by distributors and other participants in the chain of production, are paid just a fraction of their products' final price. Moreover, quite a few communities live exclusively on their own produce and market only what is superfluous.

An alternative source of income, only recently emerged and now on the rise, can be found in earnings from tourism.

\section{Conclusion}

Tourism in developing countries has been seen as an industry that can provide muchneeded economic benefits in rural and remote areas to communities that lack knowledge and financial resources to take part in tourism development without external support. New development paradigms created under the umbrella of sustainability introduced principles that support and encourage self-help, self-reliance, and empowerment of communities.

Trying to provide an example of suitable and sustainable practice, Monika Nová, the paper's author, found out that a successful project requires a careful preliminary exploration of region where the project is to be implemented, to see whether the conditions suit any form of tourism at all. The author's hands-on experience gathered not only in Cambodia but also in the countries of Africa and Latin America leads her to believe that the best kind of community-based tourism is tourism properly considering sustainable development, protection of environment and, first and foremost, the interests and benefits of the local community.

Profiting from her practice in south-east Asia and Africa, the paper's author sees the community-based tourism as an alternative solution capable of removing social and economic inequalities now afflicting rural communities. Moreover, her research results and relevant experience indicate that this kind of tourism is a tool readily available to municipalities, micro-regions and local governments wishing to make the most of their cultural and natural heritage and generate an income above what can be earned by their everyday economic activities.

The theme and research of this paper was realized from the project: NAKI II DG18P02OVV064 Právní, historické a společenskovědní aspekty nových a tradičních menšin v České republice. 


\section{References}

1. Cater, C., Garrod, B. (2015). The encyclopedia of sustainable tourism. Boston, MA: CABI.

2. Towner, J. (1995). What is Tourism's History. Tourism Management, 16(5), 339-343. https://bit.ly/2U7Ec6L

3. Beeton, S. (2006). Community development through tourism. Collingwood, Vic: Land Links.

4. Chandralal, K.P. (2010). Impacts of Tourism and Community Attitude towards Tourism: A Case Study in Sri Lanka. South Asian Journal of Tourism and Heritage, 3(2), 42-49.

5. Asker, S., Boronyak, L., Carrad, N., Paddon, M. (2010). Effective Community Based Tourism: Best Practice Manual. Sydney: Sustainable Tourism Cooperative Research Centre.

6. Asteray, M. (2011). Community Based Ecotourism: An Approach to Biodiversity Conservation and Sustainable Development. Litvia: Lambert Academic Publishing.

7. Yeo, A.W. (2012). ICT in Community Based Tourism in Bario. The eBario Experience. In Sarawak: Improvements on Social Economic Development: Proceedings of Regional Symposium on Rural Tourism 2012. Phnom Penh : Royal University of Phnom Penh, Cambodia.

8. Ahn, B., Lee, B., Shafer, S.C. (2002). Operationalizing sustainability in regional tourism planning: An application of the limits of acceptable change framework. Tourism Management, 23(1), 1-15.

9. NOVÁ, M. (2018). Dimension of migration - Challenge for European future or concern? In M. Stanickova, E. Kobarova, L. Melecky \& K. Dvorková (Eds.). Proceedings of the 4th International Conference on European Integration (pp. 10921099). Ostrava: VŠB - Technical University of Ostrava.

10. Manyara, G., Jones, E. (2007). Community-based tourism enterprises development in Kenya: An exploration of their potential as avenues of poverty reduction. Journal of Sustainable Tourism, 15(6), 628-644.

11. López-Guzmán, T., Sánchez-Cañizares, S., Pavón, V. (2011).: A Case Study. Tourismos: an International Multidisciplinary. Journal of Tourism, 6(1), 69-84.

12. Aprende de Turismo (2014). https://www.aprendedeturismo.org.

13. Aziz, R.C., Hashim, N.A.A.N., Awang, Z. (2018). Tourism development in rural areas: Potentials of appreciative inquiry approach. Journal of Tourism, Hospitality \& Culinary Arts, 10(1), 59-75.

14. Olya, H.G., Alipour, H., Gavilyan, Y. (2018). Different voices from community groups to support sustainable tourism development at Iranian World Heritage Sites: evidence from Bisotun. Journal of Sustainable Tourism, 26(10), 1728-1748.

15. Strydom, A.J., Mangope, D.J., Henama, U.S. (2019). A critique of the interface between tourism, sustainable development and sustainable tourism in communitybased tourism theory. African Journal of Hospitality, Tourism and Leisure, 8(5), 1-12.

16. Yasa, I. (2020). Community empowerment in tourism develepoment during the digital era in North Badung. South East Asia Journal of Contemporary Business, Economics and Law, 21(5).

17. Matiku, S.M., Zuwarimwe, J., Tshipala, N. (2020). Sustainable tourism planning and management for sustainable livelihoods. Development Southern Africa, Early access. 
18. Gunawan, Y., Eko, B., Yudistyana, R., Putri, D.T. (2020). Independent Community Building Model through Environmental-based Tourism Management in "Masdarling" Program. Economics Development Analysis Journal, 9(2), 208-219.

19. Mayaka, M.A., Lacey, G., Rogerson, C.M. (2020). Empowerment process in community-based tourism: Friend relationship perspective. Development Southern Africa, 37(5), 791-808.

20. Falk, A., Becker, A., Dohmen, T., Enke, B., Huffman, D., Sunde, U. (2018). Global Evidence on Economic Preferences. The Quarterly Journal of Economics, 33(4), 1645-1692.

21. Tosun, C, Dedeoğlu, B.B, Çalışkan, C, Karakuş, Y. (2020). Role of place image in support for tourism development: The mediating role of multi- dimensional impacts. International Journal of Tourism Research, 2020; Early access, 1- 19.

22. Nová, M. 2019. Globalization - its influences \& impacts on specific regions of Africa. SHS Web of Conferences, 74, 06020.

23. Paulauskaite, D., Powell, R., Coca-Stefaniak, J.A., Morrison, A.M. (2017). Living like a local: Authentic tourism experiences and the sharing economy. International Journal of Tourism Research, 19(6), 619-628.

24. Miovský, M. (2006). Qualitative approach and methods in psychological research. Praha: Grada publishing

25. Trekksoft. (2020). Travel statistics to know about in 2019 and 2020. Treksoft. https://www.trekksoft.com/en/blog/65-travel-tourism-statistics-for-2019 